\title{
Formulation of orodispersible atenolol- $\beta$-cyclodextrin tablets with co-processed crospovidone-croscarmellose sodium and poloxamer 188
}

\author{
Karina Citra Rani ${ }^{*}$, Nani Parfati ${ }^{1}$, Linda Yosanti ${ }^{2}$, \\ I Gusti Ayu Yulivia Rosa Indah ${ }^{2}$ \\ ${ }^{I}$ Department of Pharmaceutics, Faculty of Pharmacy, University of Surabaya, Indonesia \\ ${ }^{2}$ Faculty of Pharmacy, University of Surabaya, Indonesia
}

Submitted: 04-04-2019

Reviewed: 27-04-2019

Accepted: 14-08-2019

\begin{abstract}
The use of conventional tablets in geriatric patients is currently limited because of a decrease in their physiological functions, such as tremor and difficulty of swallowing pills, which lowers their compliance with drug therapy. Hypertension, one of the degenerative diseases suffered by geriatric patients, is treatable with atenolol tablets or capsules that are less soluble in water or, in other words, has a poor dissolution. This research attempted to improve the dissolution of atenolol by formulating it into orodispersible tablets (ODTs), and as such, the disintegration time was modified by adding co-processed crospovidone-croscarmellose sodium in 1:1 ratio. Moreover, Poloxamer ${ }^{\circledR} 188$ was added to the formulation of atenolol- $\beta$-cyclodextrin inclusion complex. The post-compression test revealed that ODTs disintegrated quickly within $36.67 \pm 1.21$ seconds ( $<60$ seconds) and had physical characteristics that met the pharmaceutical requirements. The amount of atenolol dissolved within 30 minutes in the dissolution study was $84.39 \%\left(\% \mathrm{Q}_{30 \text { minutes }}\right)$. The results of the accelerated stability study (at $40{ }^{\circ} \mathrm{C}$ and $\mathrm{RH} 75 \pm 5 \%$ ) for two weeks proved that the physical and chemical characteristics of the produced orodispersible atenolol tablets were stable.
\end{abstract}

Keywords: atenolol; orodispersible tablet; $\beta$-cyclodextrin; co-processed; Poloxamer 188

\footnotetext{
*Corresponding author:

Karina Citra Rani

Department of Pharmaceuticals, Faculty of Pharmacy

University of Surabaya, Indonesia

Email: karinacitrarani@staff.ubaya.ac.id
} 


\section{INTRODUCTION}

The use of conventional tablets today raises problems in geriatric patients, especially who receive long-term therapy for degenerative diseases. Patients in this age group show changes in their physiological conditions that often lead to tremor, difficulty in chewing and swallowing, and proneness to choking (Dashora, 2013). An example of degenerative diseases is hypertension (Dipiro, 2008). Atenolol is a hypertension drug that is rather difficult to dissolve in water and has low dissolution. Dissolution is a process preceding the absorption of drug substances after which the drug can provide the desired pharmacological effect for a particular time (Qiu et al., 2009).

Dissolution can be improved by modifying the physical features of the drug using specific materials to form molecular complexes (Shargel and Yu, 2017). An example of these materials is $\beta$-cyclodextrin. The outer part of $\beta$-cyclodextrin is hydrophilic, while the interior is hydrophobic (Vivek et al., 2012; Sinko, 2011). Previous research has proven how the formation of inclusion complexes can increase the dissolution of water-insoluble drugs, such as rosuvastatin. Rosuvastatin reacts to the addition of $\beta$-cyclodextrin, and in rosuvastatin- $\beta$-cyclodextrin inclusion complex, the crystallinity of this drug decreases (Akbari et al., 2011). Based on this result, the formation of atenolol- $\beta$-cyclodextrin inclusion complex is assumed to be able to increase the dissolution of atenolol.

Another strategy to improve the dissolution of atenolol is by formulating orodispersible dosage forms. Orodispersible tablets break down or dissolve quickly in the mouth without water or chewing. U.S. Food and Drug Administration defines them as tablets that can disintegrate in the oral cavity in less than 60 seconds (FDA, 2008). One way to improve the performance of superdisintegrants is co-processing, that is, the combination of two ready-made disintegrants with the appropriate process. This process is expected to optimize the disintegration of orodispersible tablets and produce materials that have better flow properties than simple mixtures of physical materials (Ramani et al., 2010). A previous study has found that the co-processing of crospovidone and croscarmellose sodium is best when composed in a 1:1 ratio (Mittapalli et al., 2010). Another study has shown the synergistic use of crospovidone and croscarmellose sodium in the formulation of orodispersible ibuprofen tablets at a total concentration of 8-10\%. The hardness and disintegration of orodispersible tablets prepared with the combination of these two superdisintegrants meet the requirements (Desai et al., 2014). The addition of surfactants in this dosage form can also help to reduce surface and interfacial tension and increase particle stability (Augsburger and Hoag, 2008). Previous studies indicate that the addition of Poloxamer 188 in the tablet matrix increases drug solubility in the matrix and accelerates drug release (Al Hanbali et al., 2018).

In this study, orodispersible atenolol tablets were created by forming atenolol- $\beta$ cyclodextrin inclusion complexes and adding Poloxamer 188, a surfactant, to improve atenolol dissolution. The crospovidone-croscarmellose sodium (1:1) was co-processed to accelerate the disintegration time of orodispersible tablets and makes the dissolution start faster. These tablets were evaluated pre- and post-compression and subjected to an accelerated stability test to determine their stability. The parameters observed in the stability test included atenolol levels, wetting time, water absorption ration, in vitro dispersion time, and dissolution.

\section{RESEARCH MATERIALS AND METHODS Materials}

The materials used in this research were atenolol p.g. (Refarmed Chemicals, Lugano Switzerland), $\beta$-cyclodextrin p.g. (Roquette, France), crospovidone (Kollidon ${ }^{\circledR}$ CL) p.g. (BASF South East Asia Pte-Ltd), croscarmellose sodium (Ac-Di-Sol) p.g., magnesium stearate p.g. (Faci Asia Pacific PTE LTD), aspartame f.g. (Ajinomoto CO.INC), Poloxamer 188 (Merck Millipore), and methylparaben (Nipagin ${ }^{\mathrm{TM}}$ ). 
The formulation of atenolol- $\beta$-cyclodextrin (1:1) inclusion complexes

The atenolol- $\beta$-cyclodextrin inclusion complex was prepared in a 1:1 molar ratio. $\beta$ cyclodextrin was dissolved in hot water, and atenolol was dissolved in heated ethanol. Then, the two solutions were mixed. This mixture was stirred continuously using a stirrer while heated at $70^{\circ} \mathrm{C}$ until the solvent evaporated, then the granules were sieved with a 60 mesh and put in the oven (Parfati et al., 2017).

The characterization of atenolol- $\beta$-cyclodextrin $(1: 1)$ inclusion complexes

The characterization of crystallographic aspects using $X$-ray diffraction

The X-ray diffraction patterns of the powder of atenolol- $\beta$-cyclodextrin (1:1) inclusion complexes were recorded with an $\mathrm{x}$-ray diffractometer (Hitachi) using $\mathrm{Cu}$ anodes set at the range of $3-80^{\circ} \mathrm{C}$ (angle $2 \theta$ ) at room temperature (Gite, 2014). The observation was performed at an angle $2 \theta$ from $5^{\circ}$ to $50^{\circ}$.

\section{Characterization with infrared spectroscopy (Fourier-transformed infrared)}

The infrared spectroscopy was used to observe changes in the functional groups of the atenolol- $\beta$-cyclodextrin (1:1) inclusion complex and compare them to the single component of the inclusion complex. The infrared spectra of atenolol, - $\beta$-cyclodextrin, and atenolol- $\beta-$ cyclodextrin (1:1) were observed in an infrared spectrophotometer (Jasco FT-IR-4200) using the $\mathrm{KBr}$ pellet method (Ghosh et al., 2011).

\section{Thermal characterization with Differential Scanning Calorimetry (DSC)}

Thermal characterization was carried out in a Differential Scanning Calorimeter (DSC) (Mettler Toledo). The samples of atenolol, $\beta$-cyclodextrin, and atenolol- $\beta$-cyclodextrin inclusion complex weighing $\pm 4 \mathrm{mg}$ were heated at a scanning rate of $10^{\circ} \mathrm{C} /$ minute from $40^{\circ} \mathrm{C}$ to $200^{\circ} \mathrm{C}$ and flowed with nitrogen at a rate of $40 \mathrm{ml} /$ minute (Gite, 2014).

\section{Characterization with Scanning Electron Microscopy}

A small amount of the sample powder $( \pm 5 \mathrm{mg})$ was prepared on an adhesive attached to the aluminum plate. The aluminum plate was then coated with gold under the atmosphere of argon gas (Ghosh et al., 2011). The prepared sample was observed under a scanning electron microscope (Hitachi SU3500).

\section{The co-processing of superdisintegrants}

The superdisintegrants were co-processed with the solvent evaporation method. Crospovidone and croscarmellose sodium were mixed with a weight ratio of 1:1 and then added with ethanol. The mixture was stirred with a magnetic stirrer until the ethanol evaporated. The wet granules were sieved with a 60 mesh, then dried in an oven at $60^{\circ} \mathrm{C}$. Afterward, the coprocessed superdisintegrants were analyzed with infrared spectroscopy and X-ray diffraction, and their moisture content was gauged.

\section{The preparation of orodispersible atenolol tablets} Table I.

The composition of the orodispersible atenolol tablets prepared in this study is presented in 
Table I The formula of orodispersible atenolol- $\beta$-cyclodextrin $(1: 1)$ tablets with coprocessed crospovidone-croscarmellose sodium and poloxamer 188

\begin{tabular}{|c|c|c|}
\hline \multirow[b]{2}{*}{ Ingredients } & \multicolumn{2}{|c|}{ Composition } \\
\hline & \% Component & $\begin{array}{c}\text { Amount per tablet } \\
(\mathbf{m g})\end{array}$ \\
\hline Atenolol- $\beta$-cyclodextrin (1:1) & $66.68 \%$ & 266.73 \\
\hline $\begin{array}{l}\text { Co-processed superdisintegrants. i.e., } \\
\text { crospovidone-croscarmellose sodium } \\
(1: 1)\end{array}$ & $10 \%$ & 40 \\
\hline Magnesium stearate & $0.5 \%$ & 2 \\
\hline Aspartame & $2.5 \%$ & 10 \\
\hline Mint flavor & $1.0 \%$ & 4 \\
\hline Aerosil & $0.5 \%$ & 2 \\
\hline Mannitol DC & $3.464 \%$ & 13.854 \\
\hline Avicel PH 102 & $13.856 \%$ & 55.856 \\
\hline Talc & $1 \%$ & 4 \\
\hline Poloxamer 188 & $0.3 \%$ & 1.2 \\
\hline Methylparaben (Nipagin) & $0.2 \%$ & 0.8 \\
\hline Total & $100 \%$ & 400 \\
\hline
\end{tabular}

After all the ingredients had been weighed, atenolol was first mixed (pre-mixed) with a portion of Aerosil in a tumbling mixer for \pm 3 minutes and then with some microcrystalline cellulose for \pm 5 minutes. Aspartame, the remaining microcrystalline cellulose, mannitol DC, and mint flavor were added to the tumbling mixer. Afterward, the co-processed superdisintegrants (crospovidone and croscarmellose sodium in 1:1 ratio) was added. The ingredients were mixed until homogeneous for \pm 10 minutes (Parfati et al., 2018). The powder mixture was evaluated precompression to ensure that it was qualified for the next procedure.

\section{Pre-compression evaluation of the powder mixture}

Flow characterization (flow rate and angle of repose)

The flow characteristics and angle of repose were determined using the fixed funnel method. The powder mixture ( \pm 100 grams) was poured through a funnel placed vertically against a horizontal plane at $10.0 \pm 0.2 \mathrm{~cm}$ high (h). The time that all powder mixture required to empty out of the funnel was recorded, and this data was used to calculate the flow rate. The height and the base radius of the conical pile of granules on the horizontal plane were measured and used to obtain the angle of repose (Aulton and Summers, 2013).

\section{Compressibility Index}

The bulk density and tapped density of the powder mixture were first measured (Aulton and Summers, 2013). The compressibility index of the powder was computed by inputting both data to the following equation:

Notes:

$$
\text { Compressibility Index }=\frac{\rho(\text { tapped })-\rho(\text { bulk })}{\rho(\text { tapped })} \times 100 \%
$$

$\rho$ (tapped): the tapped density of the powder $\rho$ (bulk): the actual (bulk) density of the powder 


\section{Hausner Ratio}

The Hausner Ratio is an indirect method for predicting the flow characteristics of the powder mixture. Its calculation involved the comparison between the tapped density and the bulk density of the powder mixture (Aulton and Summers, 2013).

\section{Moisture content}

The moisture content of the powder mixture was gauged with a moisture content analyzer. It was calculated using the following equation:

$$
\% M C=\frac{W-W o}{W o} \times 100 \% .
$$

Notes:

MC : moisture content

$\mathrm{W} \quad$ : the wet weight of powder mixture

Wo : the dry weight of powder mixture

\section{The printing of orodispersible atenolol- $\beta$-cyclodextrin (1:1) tablets with co-processed} crospovidone-croscarmellose sodium and Poloxamer 188

The orodispersible atenolol- $\beta$-cyclodextrin tablets were printed by direct compression method. Following the pre-compression evaluation, the powder mixture was mixed with an external phase (magnesium stearate, talc, and the remaining Aerosil® for 3 minutes were mixed in a tumbling mixer until homogeneous). The powder mixture was then compressed into orodispersible tablets with Erweka ${ }^{\circledR}$ tablet compression machine (force $=2$ tons). The printed tablets weighed $400 \mathrm{mg}$ and had a diameter of $11 \mathrm{~cm}$ and round, biconvex punch (Parfati et al., 2018).

\section{Post-compression evaluation}

The post-compression evaluation on the orodispersible atenolol- $\beta$-cyclodextrin tablets included organoleptic properties, size uniformity, hardness, disintegration time, friability, wetting time, water absorption ratio, in vitro dispersion time, atenolol content, and dissolution.

\section{Organoleptic properties}

During the organoleptic evaluation, the smell, color, taste, and shape of the printed orodispersible atenolol tablets were observed (Allen and Ansel, 2014).

\section{Size uniformity}

The diameter and thickness of ten tablets were measured with a micrometer to determine the physical consistency of the produced tablets (Agoes, 2012).

\section{Hardness}

Hardness is the amount of force needed to destroy a tablet during diameter testing. The orodispersible tablets were tested for hardness using a Monsanto Hardness Tester (Shahi et al., 2013).

\section{Disintegration time}

The disintegration time of the printed tablets was determined with a disintegration test apparatus (according to the United States Pharmacopeial Convention) using an aqua Purificata medium at a temperature of $37 \pm 0.5^{\circ} \mathrm{C}$. This test used six samples of these tablets (Desai et al., 2014).

\section{Friability}

A tablet sample of 6.5 gram was placed in the friability test equipment, which was operated at a speed of $25 \mathrm{rpm}$ for 4 minutes. The difference between the weights of the tablet before and after 
the test was determined (Chandrasekhar et al., 2013). The friability (\%) of the tablet was calculated using the following equation:

$$
\% \text { friability }=\frac{\text { Initial weight-Final weight }}{\text { Initial weight }} \times 100 \%
$$

\section{Wetting time and water absorption ratio}

A filter paper with a diameter of $8 \mathrm{~cm}$ was placed in a $9 \mathrm{~cm}$ petri dish. Then, the tablet was carefully placed on top of the filter paper. A total of $10 \mathrm{ml}$ of soluble dye was poured into it. The time needed for the dye to reach the top surface of the tablet was recorded as the wetting time, and the mass of water absorbed by the tablet was the water absorption ratio (Kabra et al., 2011).

\section{In vitro dispersion time}

The dispersion time of the tablets was evaluated in vitro using artificial saliva (phosphate buffer $\mathrm{pH}$ 6.8). Each tablet was placed in a container filled with $6 \mathrm{ml}$ of phosphate buffer $\mathrm{pH} 6.8$ at a temperature of $37 \pm 0.5^{\circ} \mathrm{C}$. The time it required to disintegrate was recorded as the in vitro dispersion time (Kumare et al., 2013).

\section{Content analysis}

The content of the tablet was identified with Ultra Performance Liquid Chromatography (UPLC). Ten tablets were crushed and weighed, and $\pm 400.0 \mathrm{mg}$ of the substance (equivalent to $50 \mathrm{mg}$ of atenolol powder) was put into a $100 \mathrm{ml}$ volumetric flask, added with $50 \mathrm{ml}$ of the mobile phase, and subjected to ultrasonic analysis for 5 minutes. The mobile phase was added until the etched line on the flask. One $\mathrm{ml}$ of the solution was removed to a $25 \mathrm{ml}$ volumetric flask using a pipette and diluted with the mobile phase until it reached the graduation line. The area of this solution sample was observed with a ULPC instrument, and the atenolol levels in the orodispersible tablets were measured (Departemen Kesehatan Republik Indonesia, 2014).

\section{Dissolution test}

The dissolution test of the orodispersible atenolol tablets was carried out according to the procedure described in the Farmakope Indonesia V (Departemen Kesehatan Republik Indonesia, 2014). This test used a type- 2 apparatus (paddle) at a speed of $50 \mathrm{rpm}$ for 60 minutes. Ten $\mathrm{ml}$ of the samples were extracted after 1, 3, 5, 15, 30, 45, and 60 minutes. Each solution from these sampling times was tested to determine their dissolved atenolol content using Ultra Performance Liquid Chromatography (UPLC).

\section{Stability test}

The orodispersible atenolol- $\beta$-cyclodextrin (1:1) tablets were subjected to an accelerated stability test for two weeks. The analyzed tablets were stored at $40 \pm 2{ }^{\circ} \mathrm{C} / \mathrm{RH} 75 \pm 5 \%$ and checked after two weeks. The observed parameters included wetting time, in vitro dispersion, water absorption ratio, dissolution, and the level of the active ingredient atenolol.

\section{Data Analysis}

The characteristics of the atenolol- $\beta$-cyclodextrin (1:1) inclusion complex and the data obtained from the pre- and post-compression evaluations of atenolol- $\beta$-cyclodextrin $(1: 1)$ powder were analyzed descriptively. The results of the stability test of the orodispersible atenolol- $\beta-$ cyclodextrin (1:1) tablets, which included the wetting time, in vitro dispersion, water absorption ratio, dissolution, and the level of the active ingredient atenolol, from Day 0 to Day 14 were analyzed statistically using a paired $t$-test. 


\section{RESULTS AND DISCUSSION}

The atenolol- $\beta$-cyclodextrin inclusion complex (1:1) was prepared using the solvent evaporation method. Several methods were used to characterize the resulted inclusion complex. This characterization is one technique to predict interactions and complex formation between drug molecules and $\beta$-cyclodextrin. The identified characteristics of the atenolol- $\beta$-cyclodextrin (1:1) inclusion complex with Fourier-transformed Infrared (FT-IR) are depicted in Figure 1.

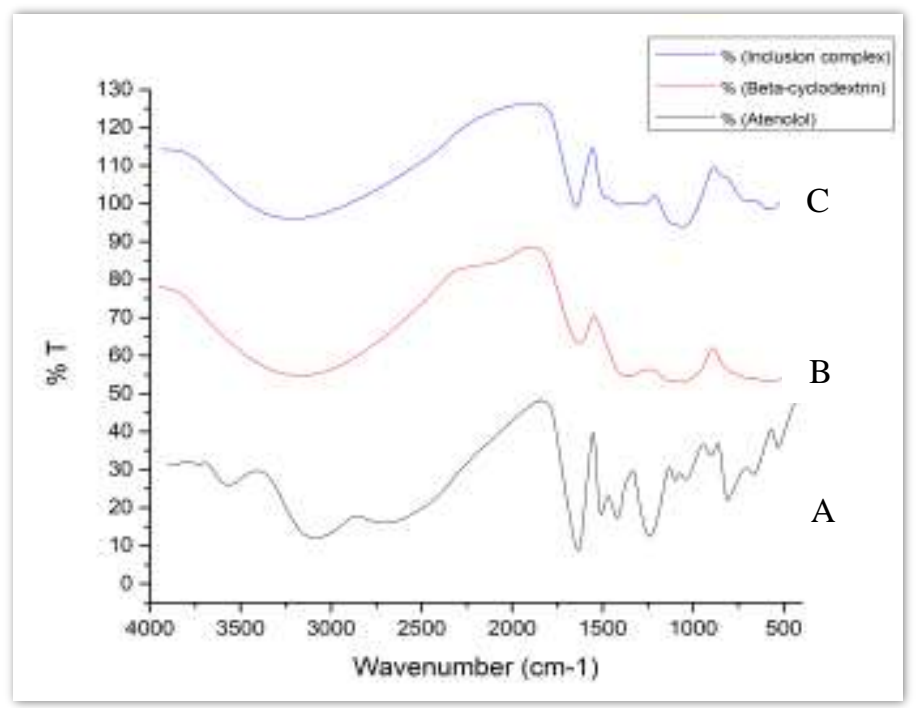

Figure 1. The visualization of the infrared spectra of (A) atenolol, (B) $\beta$-cyclodextrin, and (C) atenolol-p-cyclodextrin (1:1) inclusion complex

In this image, atenolol shows specific characteristics at wavenumbers $3355.53 \mathrm{~cm}^{-1}$, $3178.11 \mathrm{~cm}^{-1}$ (-CO-NH), $1637.27 \mathrm{~cm}^{-1}\left(-\mathrm{C}=\mathrm{O}, \mathrm{NH}\right.$ Primer), $1515.78 \mathrm{~cm}^{-1} \quad(-\mathrm{N}-\mathrm{C}=\mathrm{O}, \mathrm{NH}$ Secondary), $1418.39 \mathrm{~cm}^{-1}\left(\mathrm{H}_{2} \mathrm{~N}-\mathrm{CO}-\right)$. Meanwhile, $\beta$-cyclodextrin shows specific characteristics at $3367.1 \mathrm{~cm}^{-1}$ (OH stretching, broad), $1415.49 \mathrm{~cm}^{-1}$ (O-H bending, $\alpha-\mathrm{CH}_{2}$ bending, $\mathrm{CH}_{2}$ deformation), and $1336.43 \mathrm{~cm}^{-1}$ (O-H bending). The infrared spectrum or band of the atenolol- $\beta$ cyclodextrin inclusion complex (1:1) widens at $3355.53 \mathrm{~cm}^{-1}$. The widening of the peak is similar to the character of the infrared spectrum of $\beta$-cyclodextrin. The transmittance peak at $3178.11 \mathrm{~cm}^{-}$ ${ }^{1}$ does not appear in the infrared spectrum of the inclusion complex. These results suggest that an interaction between the functional groups of the drug molecules and the groups located in the $\beta$ cyclodextrin cavity has occurred through hydrogen bonding (Gite, 2014). In the atenolol inclusion complex, the new peak at $3724.87 \mathrm{~cm}^{-1}$ replaces the old peak of pure atenolol, i.e., at $1613.16 \mathrm{~cm}^{-}$ ${ }^{1}$. This condition suggests the loss of the - $\mathrm{CO}-\mathrm{NH}$ - group in the inclusion complex (Gite, 2014).

Based on the characterization of the crystallographic aspects, atenolol has sharp peaks with high intensity, meaning that pure atenolol has high crystallinity (Buha et al., 2012). Meanwhile, $\beta$-cyclodextrin has lower intensity than atenolol. From the diffractogram of the atenolol- $\beta$ cyclodextrin inclusion complex, a shift in the peak position and a decrease in the specific peak height of atenolol (compared to pure atenolol) are apparent. Such a decrease represents that the inclusion complex has lower crystallinity (Ghosh et al., 2011). The diffractograms of atenolol, $\beta$ cyclodextrin, and atenolol- $\beta$-cyclodextrin inclusion complex are presented in Figure 2. 


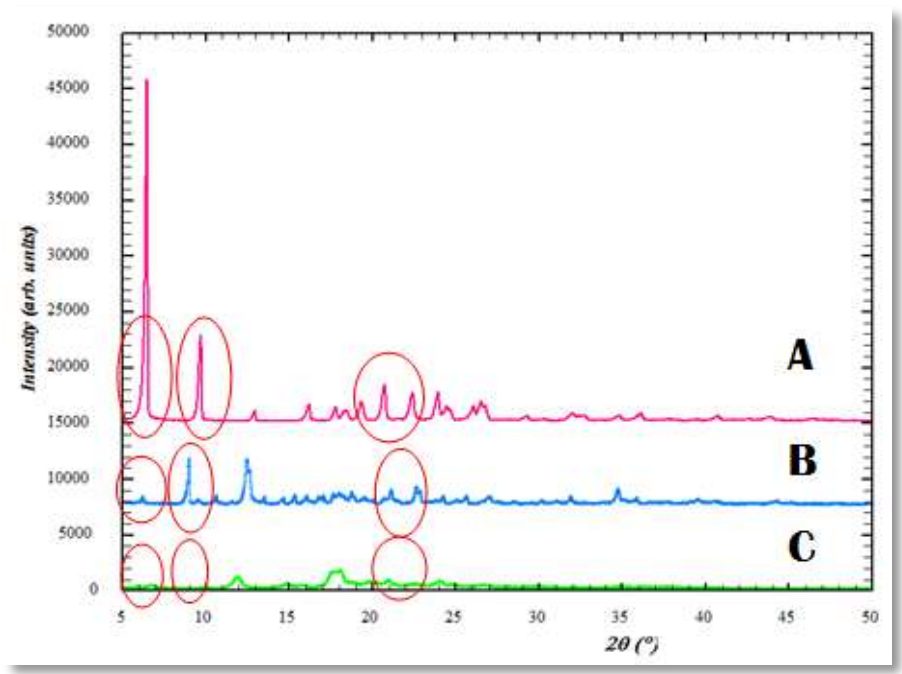

Figure 2. The characterization of (A) atenolol, (B) $\beta$-cyclodextrin, and (C) atenolol- $\beta$-cyclodextrin $(1: 1)$ inclusion complex using $X$-ray diffraction

Scanning electron microscopy was used to observe the surface morphology of the powders of atenolol, $\beta$-cyclodextrin, and inclusion complexes. Morphology is the shape and size of constituent particles of a formed system. The results of the surface morphology analysis showed that atenolol was shaped irregularly like chunks, while the $\beta$-cyclodextrin molecule had an elongated cube shape. Also, the surface morphology of the atenolol- $\beta$-cyclodextrin inclusion complex showed that the atenolol molecule was attached to the surface of $\beta$-cyclodextrin and covered by $\beta$-cyclodextrin. This condition implies that atenolol has been dispersed and adsorbed physically on the surface of $\beta$-cyclodextrin (Ghosh et al., 2011). The observation results of the morphology of atenolol, $\beta$-cyclodextrin, and the inclusion complex under a scanning electron microscope are presented in Figure 3.

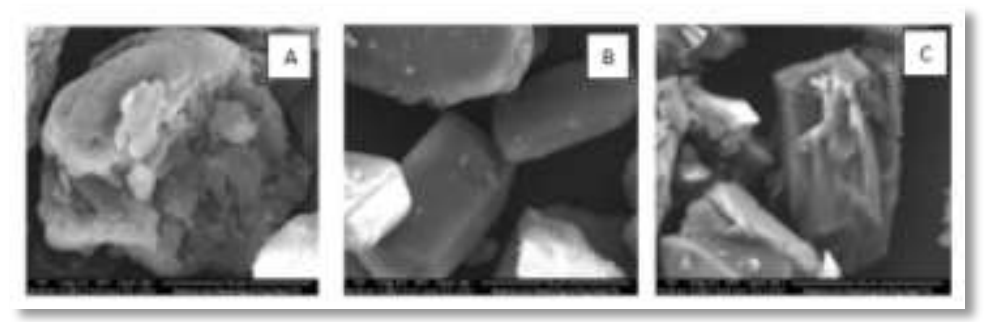

Figure 3. The observation results of the surface morphology of (A) atenolol, (B) $\beta$ cyclodextrin, and $(C)$ the atenolol- $\beta$-cyclodextrin inclusion complex under a scanning electron microscope at 5000x magnification

The thermal characteristics of atenolol, $\beta$-cyclodextrin, and the atenolol- $\beta$-cyclodextrin inclusion complex were observed with differential scanning calorimetry (DSC). The DSC thermograms of these three test subjects are presented in Figure 4. 


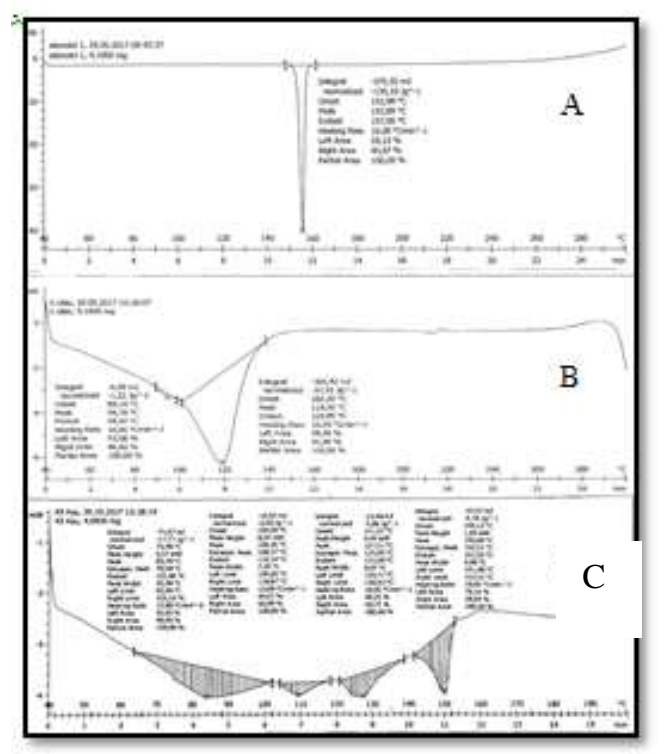

Figure 4. The thermograms of (A) atenolol, (B) $\beta$-cyclodextrin, and (C) the atenolol- $\beta$-cyclodextrin $(1: 1)$ inclusion complex resulted from differential scanning calorimetry

The DSC thermogram of atenolol shows an endothermic peak at $153.89^{\circ} \mathrm{C}$, which coincides with the melting point of atenolol, while that of $\beta$-cyclodextrin has a wide endothermic peak at around $100^{\circ} \mathrm{C}$, signifying the release of water molecules from its structure (Gite, 2014). As for the atenolol- $\beta$-cyclodextrin inclusion complex, a shift in the melting point (endothermic peak) of atenolol to $83.70^{\circ} \mathrm{C}$ is visible in the thermogram. This change means that the combination of atenolol and $\beta$-cyclodextrin has created a mixture of inclusion complex. The inclusion complex appears to have more than one endothermic peak that may be due to the dehydration from $\beta$-cyclodextrin in the range $70-110^{\circ} \mathrm{C}$ (Hadaruga et al., 2008).

The characterization of the atenolol- $\beta$-cyclodextrin inclusion complex using the infrared spectrum and differential scanning calorimetry confirmed the interactions between atenolol and $\beta$ cyclodextrin. Hydrogen bonds are formed between the $-\mathrm{CO}-\mathrm{NH}_{2}$ and- $\mathrm{NH}$ groups from the atenolol molecule with the $-\mathrm{OH}$ group in $\beta$-cyclodextrin. As observed under a scanning electron, the morphology of the atenolol- $\beta$-cyclodextrin inclusion complex affirms the existence of this interaction. This finding suggests that atenolol is dispersed in the $\beta$-cyclodextrin cavity in the form of fine particles and attaches to the surface of $\beta$-cyclodextrin. Overall, based on the results of the characterization, the atenolol- $\beta$-cyclodextrin inclusion complex has been formed.

Aside from atenolol- $\beta$-cyclodextrin inclusion complex, the characterization was performed on the co-processed crospovidone-croscarmellose sodium. It analyzed any changes in functional groups using an infrared spectrum and in crystallographic aspects using X-ray diffraction. The infrared spectra of crospovidone, croscarmellose sodium, and co-processed crospovidone-croscarmellose sodium are visualized in Figure 5. 


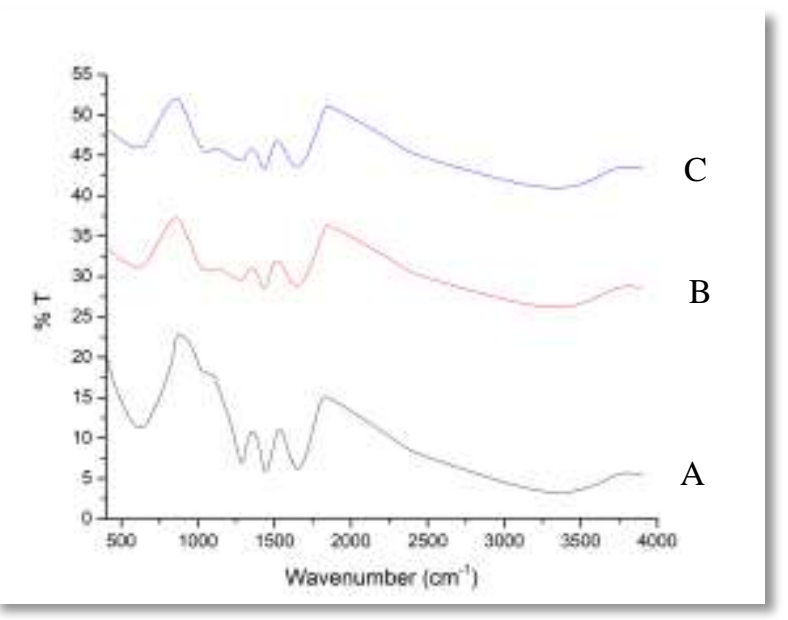

Figure 5. The visualization of the infrared spectra of (A) crospovidone, (B) croscarmellose sodium, and (C) co-processed crospovidone-croscarmellose sodium

The graph shows that crospovidone has specific absorbances at wavenumbers 1653.66 $\mathrm{cm}^{-1}(\mathrm{C}=\mathrm{O}), 1494.56 \mathrm{~cm}^{-1}, 1462.74 \mathrm{~cm}^{-1}$, and $1423.21 \mathrm{~cm}^{-1}$ (pyrrolidone group). Meanwhile, the specific absorbance of croscarmellose sodium is apparent at $3418.21 \mathrm{~cm}^{-1}(\mathrm{O}-\mathrm{H}), 2923.56 \mathrm{~cm}^{-1}$ (C-H), $1077.05 \mathrm{~cm}^{-1}$ (C-O ester), and $895.773 \mathrm{~cm}^{-1}$ (C-O-C). The observation on the functional groups in the co-processed crospovidone-croscarmellose sodium revealed a shift in the specific absorbance of crospovidone and croscarmellose sodium. The crystallographic analysis results of the co-processed crospovidone-croscarmellose sodium with X-ray diffraction are presented in Figure 6.

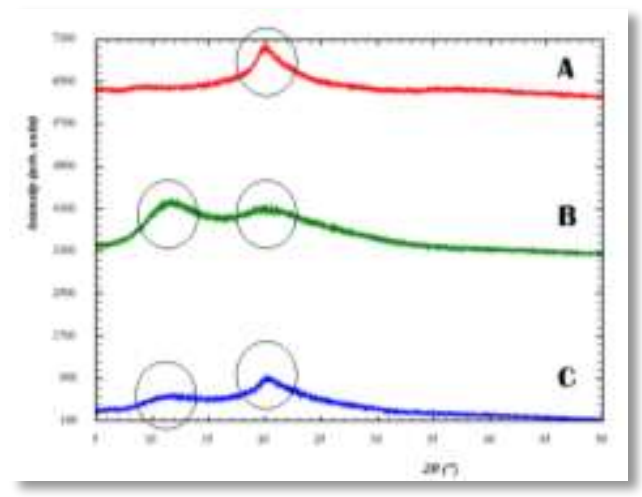

Figure 6. The visualization of the infrared spectra of (A) crospovidone, (B) croscarmellose sodium, and $(\mathrm{C})$ co-processed crospovidone-croscarmellose sodium

Based on the results of the crystallographic analysis, the height difference of the peak of the co-processed superdisintegrants indicates an interaction between croscarmellose sodium and crospovidone after co-processing. After comparing the wet weight to the dry weight of the coprocessed crospovidone-croscarmellose sodium powder, this study found that the moisture content of this powder met the pharmaceutical requirements, i.e., $2.39 \%$.

The atenolol- $\beta$-cyclodextrin inclusion complex was formulated into orodispersible tablets. The created powder mixture was subjected to pre-compression analysis, including flow characteristics, compressibility index, Hausner ratio, and moisture content. When poured through the funnel, the powder flowed at a speed of $7.44 \mathrm{~g} / \mathrm{s}$, classifying it as flowable (Hahm and 
Augsburger, 2008). This procedure created a conical pile of granular matters on the horizontal plane with an angle of repose of $31.24^{\circ}$, and the powder mixture is thereby concluded as good $\left(31-35^{\circ}\right)$ (United States Pharmacopeial Convention, 2017). Compressibility index and Hausner ratio were also used to predict the flow characteristics and the capacity of the powder mixture to form tablets (Augsburger and Hoag, 2008). The compressibility index of the powder mixture was $12.62 \%$, meaning that this powder is compressible and qualified for the compression process (Agoes, 2012; Callahan et al., 1982). Another parameter that also determines the flow properties of the powder is moisture content (Crouter and Briens, 2013). Previous research has shown that the ideal moisture content for printing tablets with cellulose microcrystalline fillers is in the range of 3-5\% (Sun, 2008). The moisture content of the orodispersible atenolol- $\beta$-cyclodextrin tablets with co-processed crospovidone-croscarmellose sodium and Poloxamer 188 in this study was $3.26 \%$.

Because the pre-compression evaluation showed that the atenolol- $\beta$-cyclodextrin powder met the requirements for tableting, it was printed into tablet dosage forms using a compression machine. The orodispersible atenolol- $\beta$-cyclodextrin tablets with co-processed crospovidonecroscarmellose sodium and Poloxamer 188 were subjected to post-compression evaluation. The organoleptic characteristics of these tablets are white, round in shape, mint odor, and sweet taste. The physical appearance of the tablet can be seen in Figure 7.

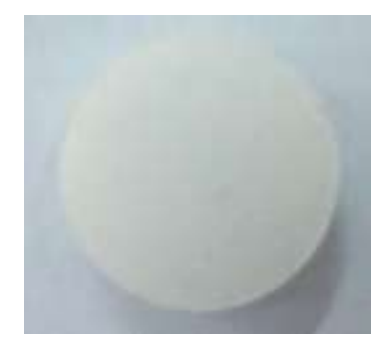

Figure 7. The physical appearance of the orodispersible atenolol- $\beta$-cyclodextrin tablet with coprocessed crospovidone-croscarmellose sodium and Poloxamer 188

The results of the post-compression evaluation are summarized in Table II. Based on the uniformity test, no size variation was found in the printed orodispersible tablets, signifying the absence of problems with the flow of the powder mixture during the tableting process. Another parameter that must be considered in the tablet formulation is hardness (Shahi et al., 2013). The hardness of the produced tablets meets the required hardness of non-coated tablets $(4-8 \mathrm{~kg})$. Other evaluations related to their mechanical characteristics are friability and abrasion (Nagar et al., 2011). The friability and abrasion test results are in line with the predefined standards for tablets with good mechanical resistance, i.e., <1\% (United States Pharmacopeial Convention, 2017). 
Table II. The results of the post-compression evaluation on the printed orodispersible atenolol- $\beta$-cyclodextrin tablets with co-processed crospovidonecroscarmellose sodium and Poloxamer 188 (The figures are the average value of three replications \pm SD)

\begin{tabular}{|c|c|c|c|}
\hline \multicolumn{2}{|c|}{ Parameters } & Specification & Mean \pm SD \\
\hline \multirow{4}{*}{$\begin{array}{l}\text { Organoleptic } \\
\text { properties }\end{array}$} & Color & White & White \\
\hline & Smell & Mint & Mint \\
\hline & Taste & Mint and sweet & Mint and sweet \\
\hline & Shape & Round & Round \\
\hline \multicolumn{2}{|c|}{ Tablet hardness $(\mathrm{kg})$} & $2-4 \mathrm{~kg}$ & $6.6 \pm 0.7$ \\
\hline \multirow{2}{*}{ Size uniformity } & Thickness & $4.00 \mathrm{~mm}$ & $4.125 \pm 0.14$ \\
\hline & Diameter & $11.00 \mathrm{~mm}$ & $11.00 \pm 0.00$ \\
\hline \multirow{2}{*}{\multicolumn{2}{|c|}{$\begin{array}{l}\text { Disintegration time (s) } \\
\text { In vitro dispersion time (s) }\end{array}$}} & $<1$ minute & $36.67 \pm 1.21$ \\
\hline & & & $104.88 \pm 0.42$ \\
\hline \multicolumn{2}{|c|}{ Friability (\%) } & $<1 \%$ & $0.30 \%$ \\
\hline \multicolumn{2}{|c|}{ Abrasion (\%) } & $<1 \%$ & $0.16 \%$ \\
\hline \multicolumn{2}{|c|}{ Wetting time (detik) } & $<3$ minutes & $96.81 \pm 1.09$ \\
\hline \multicolumn{2}{|c|}{ Water absorption ratio } & & $4.92 \% \pm 0.07$ \\
\hline \multicolumn{2}{|c|}{ Active ingredient level (\%) } & $90-110 \%$ & $98.11 \% \pm 0.21$ \\
\hline \multicolumn{2}{|c|}{ Dissolution } & $85 \%$ & $84.39 \% \pm 3.34$ \\
\hline
\end{tabular}

Wetting time and water absorption ratio illustrate the porosity and water-attracting capacity of the structure of the orodispersible atenolol- $\beta$-cyclodextrin tablets. In the wetting time evaluation, the entire surface of the tablet was wetted rapidly in $96.81 \pm 1.09 \mathrm{~s}$ because the coprocessed superdisintegrants, i.e., crospovidone-croscarmellose sodium, worked synergistically by attracting water and through capillary action (Desai et al., 2016). The calculated water absorption ratio of the tablet was $4.92 \% \pm 0.07$, meaning that the tablet absorbs water mainly through the mechanism of wicking (Al-Ghabban et al., 2013).

The wetting time has been shown to have a strong correlation with disintegration time and in vitro dispersion time (Al-Ghabban et al., 2013). It represents the initial stage that determines the disintegration time of tablets (Shankarrao et al., 2010). According to the U.S. FDA, good orodispersible tablets disintegrate in $<1$ minute (FDA, 2008). The orodispersible atenolol- $\beta$ cyclodextrin tablets produced in this study disintegrated in $36.67 \pm 1.21 \mathrm{~s}$, which is within the preferred disintegration time listed in the drug compendia. The in vitro dispersion evaluation aimed to predict the characteristics of the tablet dispersion when exposed to saliva in the oral cavity (Kaur et al., 2014). The results showed that the in vitro dispersion time ranged from 90 to $110 \mathrm{~s}$, indicating that the tablet is rapidly destroyed when placed in the oral cavity. The orodispersible atenolol- $\beta$-cyclodextrin tablets with co-processed crospovidone-croscarmellose sodium and Poloxamer 188 contained $98.11 \pm 0.21 \%$ of the active ingredient atenolol. At this concentration, they have met the required level of atenolol in a tablet dosage form according to the Farmakope Indonesia Edition V, namely 90\%-110\% (Departemen Kesehatan Republik Indonesia, 2014). Other parameters to determine the efficacy of the dosage form are dissolution process and the amount of dissolved drug in a certain period (\%Q) in a dissolution medium. The amount of dissolved atenolol in the orodispersible atenolol- $\beta$-cyclodextrin tablets in this research was $84.39 \pm 3.34 \%$, which was dissolved in 30 minutes. Although these results have not met the requirements set in the Farmakope Indonesia V (\%Q 85\%), the dissolution of atenolol is 1.4 times higher than the results of a previous study that did not use Poloxamer 188 (surfactant). The dissolution profiles of the orodispersible atenolol- $\beta$-cyclodextrin tablets with co-processed crospovidone-croscarmellose sodium and Poloxamer 188 can be seen in Figure 8 . The addition of Poloxamer 188 has been shown to reduce the interfacial tension between atenolol and the 
dissolution medium, but the optimal concentration of Poloxamer 188 in orodispersible atenolol-bcyclodextrin tablets needs to be investigated further.

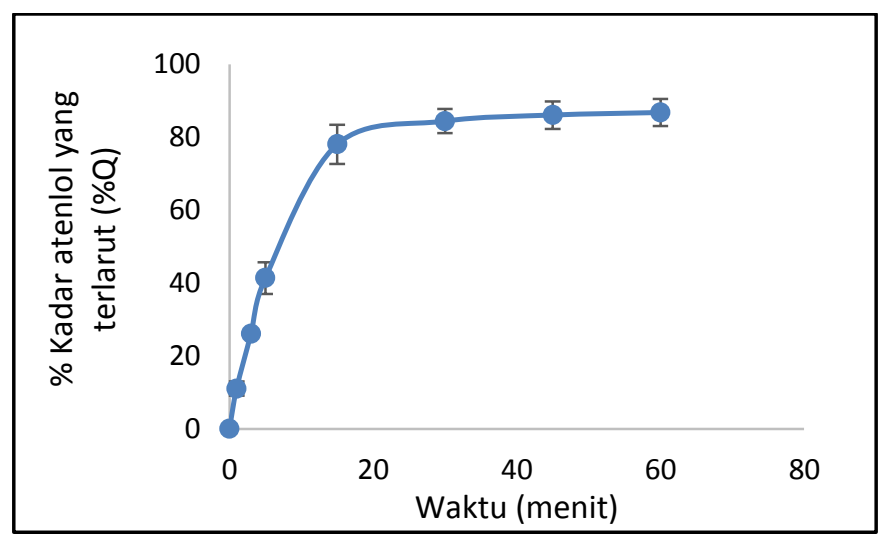

Figure 8. The dissolution profile of orodispersible atenolol- $\beta$-cyclodextrin tablets with co-processed crospovidone-croscarmellose sodium and Poloxamer 188

In this study, the orodispersible atenolol- $\beta$-cyclodextrin tablets were subjected to an accelerated stability test for two weeks. They were stored in a climatic chamber at a temperature of $40^{\circ} \pm 2^{\circ} \mathrm{C}$ and $\mathrm{RH} 75 \pm 5 \%$. This test attempted to determine the resistance of the tablet within the predefined specifications during storage and use to ensure product quality (Türkoğlu et al., 2004). The paired $t$-test with $\alpha=0.05$ confirmed that the characteristics of the tablets, as seen from the wetting time, water absorption ratio, in vitro dispersion time, atenolol content, and dissolution, did not show any significant differences. This finding denotes that the orodispersible atenolol- $\beta$ cyclodextrin tablets formulated with co-processed crospovidone-croscarmellose sodium and Poloxamer 188 are stable in two-week storage at $40^{\circ} \pm 2^{\circ} \mathrm{C}$ dan $\mathrm{RH} 75 \pm 5 \%$.

\section{CONCLUSION}

The atenolol- $\beta$-cyclodextrin inclusion complex prepared using the solvent evaporation method can be developed into an orodispersible tablet after direct compression. The addition of co-processed crospovidone-croscarmellose sodium into the formulation of orodispersible atenolol- $\beta$-cyclodextrin tablets can accelerate tablet disintegration and, therefore, dissolution can occur faster. The addition of Poloxamer 188 has been proven to increase the dissolution of atenolol from orodispersible tablets by 1.4 times than previous studies, but it has not met the requirements set in the Farmakope Indonesia, that is, $85 \%$ of atenolol dissolved within 30 minutes. Further research to determine the optimal concentration of Poloxamer 188 to improve atenolol dissolution is recommended.

\section{ACKNOWLEDGMENT}

Authors would like to express their gratitude to the Directorate General of Research and Development Strengthening (DPRM) under the Ministry of Research, Technology and Higher Education of the Republic of Indonesia and the Institute of Research and Community Services (LPPM) of University of Surabaya for funding this research under the 2018 National Strategic Research (PSN) scheme.

\section{REFERENCES}

Agoes G, 2012, Sediaan Farmasi Padat $1^{\text {st }}$ edition. Bandung: Penerbit ITB.

Akbari, B. V., Valaki, B.P., Maradiya, V.H., Akbari, A.K., Vidyasagar, G., 2011. Effect of Types of Cyclodextrin on Rosuvastatin Calcium Inclusion Complex, Indian Journal of Pharmacy, 2, 1-8. 
Al-Ghabban, F.M., Al-Ani, I.H., Hassan, S.F., Salan, N., 2013, Formulation of Prifinium Bromide and Prifinium Bromide-Diclofenac Sodium combination as orodispersible tablets, International Journal of Pharmacy and Pharmaceutical Sciences, 5: 652-659.

Al Hanbali, O.A., Hamed, R., Arafat, M., Bakkour, Y., Al-Matubsi, H., Mansour, R., AlBataineh, Y., Aldhoun, M., Sarfraz, M., Yousef Dardas, A.K., 2018, Formulation and evaluation of diclofenac controlled release matrix tablets made of HPMC and Poloxamer 188 polymer: An assessment on mechanism of drug release., Pakistan Journal of Pharmaceutical Sciences, 31: 345-351.

Allen, L. V, Ansel, H.C., 2014, Ansel's Pharmaceutical Dosage Forms and Drug Delivery Systems, Philadelphia: Wolters Kluwer Health.

Augsburger, L.L., Hoag, S.W., 2008, Pharmaceutical Dosage Forms-Tablets, in Pharmaceutical Dosage Forms: Tablets. New York: Informa Healthcare.

Aulton M, Summers M, 2013, Aulton's Pharmaceutics The Design and Manufacture of Medicines. Philadelphia: Churchill Livingstone.

Buha, S.M., Baxi, G.A., Shrivastav, P.S., 2012, Liquid Chromatography Study on Atenolol-Cyclodextrin Inclusion Complex, ISRN Analytical Chemistry, 2012.

Callahan, J.C., Cleary, G.W., Elefant, M., Kaplan, G., Kensler, T., Nash, R.A., 1982, Equilibrium moisture content of pharmaceutical excipients, Drug Development and Industrial Pharmacy, 8: 355-369.

Chandrasekhar, P., Shahid Muhammad, S., Niranjan Babu., M., 2013, Formulation and Evaluation of Oral Dispersible Tablets of Anti Hypertensive Drug Atenolol, International Journal of Pharmacy, 3: 79-84.

Crouter, A., Briens, L., 2013, The Effect of Moisture on the Flowability of Pharmaceutical Excipients, American Association of Pharmaceutical Scientist, 15(1): 65-74.

Dashora, K., 2013, Formulation and Evaluation of Fast Dissolving Tablets Atenolol, Journal of Chemical and Pharmaceutical Sciences, 6(2): 113-119.

Departemen Kesehatan Republik Indonesia, 2014, Farmakope Indonesia Edisi V, Departemen Kesehatan Republik Indonesia, Jakarta.

Desai, P.M., Er, P.X.H., Liew, C.V., Heng, P.W.S., 2014, Functionality of Disintegrants and Their Mixtures in Enabling Fast Disintegration of Tablets by a Quality by Design Approach, American Association of Pharmaceutical Scientist, 15(5): 1093-1104.

Desai, P.M., Liew, C.V., Heng, P.W.S., 2016, Review of Disintegrants and the Disintegration Phenomena, Journal of Chemical and Pharmaceutical Sciences, 105(9): 2545-2555.

Dipiro, E. Al, 2008, Pharmacotherapy: A Pathophysiological Approach. New York: McGraw Hill Medical.

Food and Drug Administration (FDA), 2008, Guidance for industry: orally disintegrating tablets. Cent. Drug Eval. Res. 1-3.

Ghosh, A., Biswas, S., Ghosh, T., 2011, Preparation and Evaluation of Silymarin $\beta$-cyclodextrin Molecular Inclusion Complexes, Journal of Young Pharmacist, 3(3): 205-210.

Gite, S., 2014, Development and Evaluation of Mucoadhesive Tablets of Atenolol and It's BCyclodextrin Complex, Asian Journal of Biomedical and Pharmaceutical Sciences, 4(37): $25-32$.

Hadaruga, D.I., Hadaruga, N.G., Hermenean, A., Rivis, A., Paslaru, V., Codina, G., 2008, Bionanomaterials: Thermal Stability of the Oleic Acid/alpha- and beta-cyclodextrin Complexes, Revista De Chimie, 59(9): 994-998.

Hahm, H.A., Augsburger, L.L., 2008, Orally disintegrating tablets and related tablet formulations, in: Pharmaceutical Dosage Forms: Tablets. New York: Informa Healthcare.

Kabra, A.O., Shah, F.B., Wanare, R.S., April, M., 2011, Formulation and In-Vitro evaluation of rapidly disintegrating tablets using captopril as a model drug, International Journal of Pharmaceutical Sciences Review and Research, 7(2), 206-210. 
Kaur, G., Jaiswal, S., Gupta, G.D., 2014, Formulation and Evaluation of Melt in Mouth Tablet by Solid Dispersion Technique, Indo American Journal of Pharmacaeutical Research, 4 (6): 2897-2909.

Kumare, M.M., Marathe, R.P., Kawade, R.M., Ghante, M.H., Shendarkar, G.R., 2013, Design of fast dissolving tablet of Atenolol using novel co-processed superdisintegrant, Asian Journal of Pharmaceutical and Clinical Research, 6(3): 81-85.

Mittapalli, R.K., Sha Qhattal, H.S., Lockman, P.R., Yamsani, M.R., 2010, Varying efficacy of superdisintegrants in orally disintegrating tablets among different manufacturers, Pharmazie, 65(11): 805-810.

Nagar, P., Singh, K., Chauhan, I., Verma, M., Yasir, M., Khan, A., Sharma, R., Gupta, N., 2011, Orally disintegrating tablets: formulation, preparation techniques and evaluation, Journal of Applied Pharmaceutical Science, 1(4): 35-45.

Parfati, N., Rani, K.C., Charles, N., Geovanny, V., Pradnya, D.P., n.d. 2017, Formulasi Orally Disintegrating Tablet Atenolol- $\beta$-cyclodextrin Sodium Starch Glycolate, Media Pharmaceutica Indonesiana, 1(4): 197-203.

Parfati, N., Rani, K.C., Meilany, 2018, The effect of coprocessed superdisintegrants ratio (Crospovidone-sodium starch glycolate) to the physicochemical characteristics of atenolol orally disintegrating tablets, Asian Journal of Pharmaceutical and Clinical Research, 11(2): 318-324.

Qiu, Y., Chen, Y., Zhang, G., Liu, L., Porter, W., 2009, Developing solid oral dosage forms. Pharmaceutical theory and practice. New York: Elsevier.

Ramani, R.G., Road, S., Address, C., 2010, Novel Co-Processed Superdisintegrants in The Design of Fast Dissolving Tablets, International Journal of Pharma and Bio Sciences, V1(1), 1-12.

Shahi, S.R., Kanzarkar, M. V., Khadabadi, S.S., Zadbuke, N., 2013, Formulation and evaluation of atenolol orodispersible tablets by phase transition technology, International Journal of Pharmacy and Pharmaceutical Sciences, 5(4): 604-609.

Shankarrao, K.A., Mahadeo, G.D., Balavantrao, K.P., 2010, Formulation and in-vitro evaluation of orally disintegrating tablets of olanzapine-2-hydroxypropyl- $\beta$-cyclodextrin inclusion complex. Iranian Journal of Pharmaceutical Research, 9(4): 335-347.

Shargel, L., Yu, A.B.C., n.d, 2015, Applied Biopharmaceutics and Pharmacokinetics seventh edition. New York: McGraw Hill Education.

Sinko, P., 2011, Martin's Physical Pharmacy And Pharmaceutical Sciences. Philadelphia: Wolters Kluwer Health.

Sun, C.C., 2008, Mechanism of moisture induced variations in true density and compaction properties of microcrystalline cellulose, International Journal of Pharmaceutics, 346(1-2): 93-101.

Türkoğlu, M., Varol, H., Çelikok, M., 2004, Tableting and stability evaluation of enteric-coated omeprazole pellets, European Journal of Pharmaceutics and Biopharmaceutics, 57(2): 279-286.

United States Pharmacopeial Convention, 2017, U.S. Pharmacopeia National Formulary, The United States Pharmacopeial Convention, Rockville.

Vivek, R., Shailendra, P.S., Sheory, R. V, 2012, Formulation and Evaluation of Orally Disintegrating Tablets of Atenolol with Cyclodextrin Inclusion Complex, International Journal of Drug Discovery and Herbal Research, 2: 461-464. 
